\title{
KUALITAS HIDUP PASIEN KANKER GINEKOLOGI YANG MENJALANI TERAPI
}

\author{
Riska Hediya Putri \\ STIKes Aisyah Pringsewu Lampung; Jalan A.Yani No. 1A Tambahreho, Gadingrejo, \\ Pringsewu, 085669635373 \\ Email: riskahediya17@gmail.com
}

\begin{abstract}
ABSTRAK
Meningkatkan kualitas hidup pasien kanker selama terapi akan meningkatkan kepatuhan mereka akan perawatan dan pengobatan serta memberikan mereka kekuatan untuk mengatasi berbagai keluhan yang dialami pasien kanker.Penelitian cross-sectional ini bertujuan untuk mengidentifikasi kualitas hidup pasien kanker ginekologi yang menjalani terapi. Teknik consecutive sampling dilakukan untuk memilih 153 pasien kanker ginekologi. Hasil penelitian menunjukan bahwa sebagian besar pasien kanker ginekologi mempunyai kualitas hidup domain kesehatan global dan domain fungsional tergolong tinggi tetapi untuk domain gejala masih tergolong rendah.Hasil analsis data diketahui bahwa nilai rerata kualitas hidup global domain kesehatan umum adalah 67,55. Pada domian fungsional ditemukan bahwa fungsi emosional memilki nilai rata-rata tertinggi yaitu 83,60. Pada domain gejala menunjukkan bahwa gejala insomnia memilki nilai rerata tertinggi yaitu 46,62. Penilaian kualitas hidup membuktikan bahwa tidak hanya penting untuk mengatasi gejala kanker secara optimal akan tetapi dapat juga sebagai informasi tambahan dalam mengevaluasi hasil dari pengobatan.
\end{abstract}

Kata kunci : Kualitas hidup, kanker ginekologi, terapi

\section{THE QUALITY OF LIFE GYNECOLOGY CANCER UNDERGOING THERAPY}

\begin{abstract}
Improved quality of life of cancer patients during the therapy may increase their treatment and empower them adherence to overcome any complains experienced by cancer patients. This cross-sectional research objective to identify the quality of life of the gynecology cancer patients who undergoing therapy. Consecutive sampling technique was performed to select 153 gynecology cancer patients. The results of the research indicated that most of the gynecology cancer patients required high level of quality of life on global health and functional domains.However, the quality of life on the symptom domain was quite low. The result showed that the mean value the quality of life in global health domain is 67,55. The quality of life in functional domain reported that the emotional function had the highest mean value 83,60. The quality of life in symptoms domain reported that insomnia had the highest mean value 46,62. The quality of life reported that is important to treat cancer symptoms optimally, it alsa can be additional information to evaluate the outcome of the treatment.
\end{abstract}

Keywords: Quality of life, gynecology cancer, therapy

How to Cite: Putri, R. H. (2017). Kualitas Hidup Pasien Kanker Ginekologi yang Menjalani Terapi. Aisyah: Jurnal Ilmu Kesehatan. 2 (1), 69 - 74. 


\section{Aisyah: Jurnal Ilmu Kesehatan 2 (1) 2017, - 70}

Riska Hediya Putri

\section{PENDAHULUAN}

Kanker ginekologi merupakan salah satu jenis kanker yang sering terjadi pada wanita setelah kanker payudara, kanker usus besar dan kanker paru. Berdasarkan estimasi Globocan, IARC tahun 2012, kanker serviks dan kanker ovarium merupakan kanker ginekologi yang paling sering terjadi di Indonesia. Insiden kanker serviks yaitu 17,3/100.000 wanita per tahun dan kanker ovarium sebesar 8,4/100.000 wanita pertahun (Ferlay et al, 2014). Kanker sendiri telah dikenal sebagai salah satu penyakit yang memilki dampak serius terhadap fisik dan psikologis bagi penderitanya.

Kanker telah dikenal sebagai salah satu penyakit yang memilki dampak serius terhadap fisik dan psikologis bagi penderitanya. Perkembangan dalam deteksi dan pengobatan kanker telah sangat membantu mengurangi angka kematian akibat kanker namunterdiagnosis kanker masih merupakan stressor yang mendalam bagi penderitanya dan hal ini berhubungan terhadap persepsi masyarakat mengenai penyakit kanker yang identik dengan kematian, rasa sakit dan penderitaan (Kashani, Vaziri, Akbari, Jamshidifar, \& Sanaei, 2014; Vella \& Budd, 2011).

Diagnosis dan pengobatan kanker berdampak signifikan terhadap kesejahteraan fisik, psikologis, informasi dan sosial, sehingga memerlukan dukungan kebutuhan perawatan yang kuat. Gangguan fungsi fisik sering dikaitkan dengan gejala distress, yang keduanya dapat menyebabkan kesulitan dalam beraktivitas sehari-hari dan meningkatkan kebutuhan pelayanan suportif yang tidak terpenuhi (Liao et al., 2012).

Kualitas hidup merupakan tujuan penting dalam pengobatan kanker, dan kekhawatiran akan kondisi fisik, psikologis, gangguan citra tubuh, serta gejala-gejala yang dapat menimbulkan distress perlu segera diantisipasi untuk meningkatkan kualitas hidup pasien kanker. Meningkatkan kualitas hidup pasien kanker selama pengobatan akan meningkatkan kepatuhan mereka akan perawatan dan pengobatan serta memberikan mereka kekuatan untuk mengatasi berbagai gejala atau keluhan yang dialami pasien kanker (Bayram, Durna, \& Akin, 2014).

Penelitian Perwitasari, (2009) yang menilai kualitas hidup pasien kanker yang menjalani kemoterapi di RSUP Sardjito Yogyakarta menunjukkan bahwa kualitas hidup pasien kanker mengalami penurunan setelah melakukan terapi kemoterapi. Upaya peningkatan kualitas hidup pasien kanker salah satunya dengan mengantisipasi gejala-gejala fisik dan psikologis yang dirasakan. Oleh karena itu identifikasi kualitas hidup pasien kanker harus dipahami baik oleh tenaga kesehatan maupun keluarga.

\section{METODE}

Penelitian ini merupakan penelitian korelasi dengan pendekatan cross-sectional. Sampel penelitian ini adalah pasien kanker serviks dan kanker ovarium yang sedang menjalani terapi di RS Kanker Dharmais dan RSPAD Gatot Soebroto sebanyak 153 responden. Consecutive sampling digunakan untuk menentukan sampel tersebut.

Instrumen untuk mengukur kualitas hidup pasien kanker adalah European Organozation of Research and Treatment of Cancer Quality of Life Q-C30 (EORTC QLQ-30), Quality of Life Questonnaire Cervical Cancer Module (EORTC QLQCX 24) dan Quality of Life Questonnaire Ovary Cancer Module (EORTC QLQOV28).

Kuesioner EORTC QLQ-30 berisi 30 pertanyaan yang terdiri dari 3 domain yaitu domain status kesehatan umum, domain fungsional, dan domain gejaladengan nilai validitas $0,14-0,48$ dan reabilitas $>0,70$. KuesionerEORTC QLQ-CX24 terdiri dari 24 pertanyaan yang terdiri dari 2 domain 
Aisyah: Jurnal Ilmu Kesehatan 2 (1) 2017, - 71

Riska Hediya Putri

yaitu domain faktor fungsional. Kuesioner EORTC QLQ-OV28 terdiri dari 28 pertanyaan yang terdiri dari 2 domain yaitu domain faktor fungsional dan faktor gejala dengan nilai uji validitas $0.304-0.787$ dengan reabilitas 0,872 .

Analisis pada penelitian ini adalah analisis univariat dan analisis bivariat. Analisis univariat menggunakan distribusi frekuensi. Analisis bivariat untuk mengetahui hubungan antara karakteristik reponden dengan kualitas hidup pasien kanker ginekologi yang menjalani terapi menggunakan uji korelasi spearman. Penelitian ini telah mendapatkan ijin etik dari Fakultas Ilmu Keperawatan Universitas Indonesia dan RS Kanker Dharmais.

\section{HASIL DAN PEMBAHASAN}

Seluruh responden sebanyak 153 berpartisipasi dalam penelitian ini. Hasil analisis karakteristik responden seperti pada tabel 1 dan analisis kualitas hidup pada tabel 2.

Tabel 1

Karakteristik Responden Penelitian

\begin{tabular}{lcc}
\hline \multicolumn{1}{c}{ Variabel } & $\begin{array}{c}\text { Frekuensi } \\
\text { (n) }\end{array}$ & $\begin{array}{c}\text { Presentase } \\
(\%)\end{array}$ \\
\hline Jenis Kanker & & \\
Kanker serviks & 99 & 64.7 \\
Kanker ovarium & 54 & 35.3 \\
$\begin{array}{l}\text { Stadium Kanker } \\
\text { Stadium awal } \\
\text { (Stadium I dan II) }\end{array}$ & 104 & \\
$\begin{array}{l}\text { Stadium akhir } \\
\text { Stadium III dan IV) }\end{array}$ & 49 & 68 \\
Lama Terapi & & \\
Kanker \\
$\leq 1$ tahun
\end{tabular}

Tabel 2

Kualitas Hidup Responden Penelitian

\begin{tabular}{|c|c|}
\hline Variabel & Mean (SD) \\
\hline \multicolumn{2}{|l|}{ Kualitas Hidup Global } \\
\hline Status Kesehatan Umum & $67.65(19.02)$ \\
\hline Fungsional & 73.89 (14.99) \\
\hline Fungsi Fisik & $63.83(63,83)$ \\
\hline Fungsi Peran & $59.91(59.91)$ \\
\hline Fungsi Emosional & $83.60(83.60)$ \\
\hline Fungsi Kognitif & $88.34(88.34)$ \\
\hline Fungsi Sosial & $76.47(76.47)$ \\
\hline Gejala & $28.89(15.04)$ \\
\hline Kelelahan & $44.59(14.41)$ \\
\hline Mual dan Muntah & $23.31(23.90)$ \\
\hline Nyeri & $39.32(25.84)$ \\
\hline Sesak Nafas & $17.43(24.80)$ \\
\hline Insomnia & $46.62(37.33)$ \\
\hline Hilang Nafsu Makan & $43.36(29.14)$ \\
\hline Konstipasi & $21.13(36.42)$ \\
\hline Diare & $71.24(23.89)$ \\
\hline Kesulitan Keuangan & $16.99(21.67)$ \\
\hline \multicolumn{2}{|l|}{ Kualitas Hidup Kanker Serviks } \\
\hline Fungsional & $79.50(14.15)$ \\
\hline Gambaran Diri & $68.33(41.69)$ \\
\hline Aktivitas Seksual & $66.67(27.21)$ \\
\hline Kenikmatan Seksual & $50.00(19.24)$ \\
\hline Fungsi Seksual & $93.75(4.16)$ \\
\hline Gejala & $34.55(10.44)$ \\
\hline Gejala yang dirasakan & $36.26(7.42)$ \\
\hline Lymphoedema & $8.33(16.67)$ \\
\hline Neuropati Perifer & $58.33(41.94)$ \\
\hline Gejala Menopause & $23.56(27.46)$ \\
\hline Kecemasan Seksual & $75.00(16.67)$ \\
\hline \multicolumn{2}{|l|}{ Kualitas Kanker Ovarium } \\
\hline Fungsional & $79.69(10.25)$ \\
\hline Gambaran Diri & $79.32(17.11)$ \\
\hline Seksualitas & $93.82(17.22)$ \\
\hline Prilaku terhadap pengobatan & $69.75(16.64)$ \\
\hline Gejala & $27.29(9.7)$ \\
\hline Gejala Pencernaan & $21.87(11.46)$ \\
\hline Neuropati Perifer & $36.62(22.59)$ \\
\hline Gejala Menopause & $19.44(15.77)$ \\
\hline Efek lain Kemoterapi & $25.18(13.37)$ \\
\hline Kerontokan Rambut & $44.44(28.22)$ \\
\hline
\end{tabular}

Tabel3

Hubungan Karakteristik Responden dengan kualitas hidup

\begin{tabular}{lcc}
\hline \multirow{2}{*}{\multicolumn{1}{c}{ Variabel }} & \multicolumn{2}{c}{ Kualitas Hidup } \\
\cline { 2 - 3 } & $\mathbf{r}$ & $\boldsymbol{p}$ value \\
\hline Jenis Kanker & -0.057 & 0.484 \\
\hline Stadium Kanker & 0.009 & 0.916 \\
\hline Lama Terapi & 0.086 & 0.293 \\
Kanker & & \\
\hline Jenis Terapi & 0.054 & 0.509 \\
\hline
\end{tabular}




\section{Aisyah: Jurnal Ilmu Kesehatan 2 (1) 2017, - 72}

Riska Hediya Putri

Kualitas hidup pasien kanker juga dipengaruhi oleh beberapa faktor yaitu pendidikan, pendapatan, waktu dan jarak yang dibutuhkan untuk ke RS, stadium kanker, lama pengobatan, jenis pengobatan dan jenis kanker yang diderita (Bayram et al., 2014; Bifulco et al., 2012; So et al., 2014). Pada penelitian ini didapatkan hasil bahwa variabel perancu (stadium kanker, lama terapi, jenis terapi dan jenis kanker) tidak ada hubungan dengan kualitas hidup pasien kanker ginekologi yang menjalani terapi. Berbeda dengan Susilowati (2012) yang meneliti faktor-faktor kualitas hidup pasien kanker payudara didapatkan hasil bahwa stadium kanker, lama terdiagnosa kanker dan jenis pegobatan sangat mempengaruhi kualitas hidup pasien kanker payudara.

Perbedaan hasil penelitian ini dapat disebabkan oleh perbedaan sampel yang diambil, pada penelitian susilowati sampel yang diambil adalah pasien kanker payudara, sedangkan dalam penelitian ini sampel yang diambil yaitu pasien kanker serviks dan kanker ovarium. Penelitian yag dilakukan oleh Amatya et al (2014) yang melihat perbedaan antara kanker payudara dan tumor otak pada kebutuhan pelayan suportif, kesejahteraan psikologis dan kualitas hidup, didapatkan hasil bahwa terdapat perbedaan kecemasan dan kualitas hidup yang dirasakan oleh pasien kanker payudara dan tumor otak. Pasien kanker payudara lebih tinggi tingkat kecemasannya akan kematian

Kualitas hidup pasien dalam penelitian ini dinilai dalam beberapa bagian yaitu kualitas hidup global, kualitas hidup kanker serviks dan kualitas hidup kanker ovarium. Setiap penilaian terbagi dalam beberapa domain yaitu domain kesehatan umum, domain fungsional dan domain gejala.

Pada domain fungsional, semakin tinggi skor menunjukkan tingkat respon yang lebih tinggi. Sehingga nilai atau skor tinggi pada domain fungsional menunjukkan fungsi kesehatan yang tinggi pula, apabila menunjukan skor atau nilai yang tinggi maka kualitas hidupnya tinggi atau baik, sedangkan kualitas hidup domain gejala apabila skor menunjukkan tinggi, maka gejala atau masalah yang dialami juga tinggi (du Toit \& Kidd, 2015; Fayers \& Bottomley, 2002). Penilaian kualitas hidup membuktikan bahwa tidak hanya penting untuk mengatasi gejala kanker secara optimal akan tetapi dapat juga sebagai informasi tambahan dalam mengevaluasi hasil dari pengobatan (Merane et al., 2012).

Kesejahteraan emosional merupakan aspek yang terkena dampak paling negatif selama pasien menjalani kemoterapi. Pasien kanker yang menjalani terapi membutuhkan dukungan emosional untuk mengatasi kekhawatiran, kesedihan, dan ketakutan selama proses diagnosis dan pengobatan (Butow et al., 2014). Walaupun pasien mengalami berbagai macam kondisi yang meningkatkan kecemasannya, pasien tetap merasa optimis dan tetap melakukan yang terbaik selama menjalani terapi hal ini dikarekan juga pasien menerima dukungan emosional yang cukup baik dari keluarga dan teman-teman sesama pasien kanker yang menjalani terapi, hal ini yang mungkin dapat berhubungan dengan peningkatan kualitas hidup pasien kanker ginekologi yang menjalani terapi. Pada penelitian telah dilakukan untuk melihat atau menilai seberapa besar atau tinggi kebutuhan pelayanan suportif dan kualitas hidup pasien kanker ginekologi yang menjalani terapi.

\section{KESIMPULAN DAN SARAN}

Hasil penelitian menunjukan bahwa sebagian besar pasien kanker ginekologi mempunyai kualitas hidup domain kesehatan global dan domain fungsional tergolong tinggi tetapi untuk domain gejala masih tergolong rendah. Untukmeningkatkan kualitas hidup pasien kanker perlu adanya pengakajian atau indentifikasi kebutuhan pelayanan ini sejak pasien terdiagnosa, menjalani terapi dan 


\section{Aisyah: Jurnal Ilmu Kesehatan 2 (1) 2017, - 73}

Riska Hediya Putri

ketika selesai proses terapi. Penelitian ini perlu dikembangkan dengan melakukan penelitian penelitian pada pasien yang terdiagnosa kanker untuk mengetahui kebutuhan pelayanan suportif yang diperlukan dan hubungannya dengan kualitas hidup dengan metode kuantitatif.

\section{DAFTAR PUSTAKA}

Amatya, B., Khan, F., Ng, L., \& Galea, M. (2014). Supportive care needs following cancer treatment: A comparison of breast and brain cancer in an Australian Cohort. ISRN Rehabilitation, 2014, 1-10. doi: http://dx.doi.org/10.1155/2014/94547 2

Baryam, Z., Durna, Z., \& Akin, S. (2014). Quality of life during chemotherapy and satisfaction with nursing care in Turkish breast cancer patients. European Journal of Cancer Care, 23, 675-684. doi: 10.1111/ecc.12185

Bifulco, G., Rosa, N. De, Tornesello, M. L., Piccoli, R., Bertrando, A., Lavitola, G., Nappi, C. (2012). Quality of life, lifestyle behavior and employment experience: A comparison between young and midlife survivors of gynecology early stage cancers. Gynecologic Oncology, 124(3), 444451.

http://doi.org/10.1016/j.ygyno.2011.1 1.033

Butow, P.N., Price, M.A., Bell, A.L., Webb, M.P., deFazio, A. (2014). Caring for women with ovarian cancer in the last year of life: A longitudinal study of caregiver quality of life, distress and unmet needs. Gynecologic Oncology, 123, 690-679. doi: 10.1016/j.ygyno.2014.01.002.

Du Toit, G.C., \& Kidd, M. (2015). Prospective quality of life study of south african women undergoing treatment for advanced-stage cervical cancer. Clinical Therapeutics, 37(10), 2324-2331. doi: http://dx.doi.org/10.1016/j.clinthera.2 015.08.081.

Fayers, P., \& Bottomley, A. (2002). Quality of life research within the EORTC the EORTC QLQ-C30. European 


\section{Aisyah: Jurnal Ilmu Kesehatan 2 (1) 2017, - 74}

Riska Hediya Putri

Journal of Cancer, 38, 125-133. doi: 10.1016/s0959-8049(01)00448-8.

Ferlay, J., Soerjomataram, I., Ervik, M., Forman, D., Bray, F., Dikshit, R., ... Parkin, D.M. (2014). Globocan 2012: Estimated Cancer Incidance, Mortality and Prevalence Worldwide in 2012. Retrived from http://globocan.iarc.fr/Pages/fact_she ets_population.aspx.

Kashani, F. L., Vaziri, S., Akbari, M. E., Jamshidifar, Z., \& Sanaei, H. (2014). Stress Coping Skills Training and Distress in Women with Breast Cancer. Procedia - Social and Behavioral Sciences, 159, 192-196. http://doi.org/10.1016/j.sbspro.2014.1 2.355 .

Lioa, M.N., Chen, S.C., Chen, S.C., Lin, Y.C., Hsu, Y.H., Hung, H.C., ... Jane, S.W. (2012). Changes and Predictors of Unmet Supportive Care Needs in Taiwanese Women With Newly Diagnosed Breast Cancer. Oncology Nursing Forum, 39(5), 380-389.

Meraner, V., Gamper, E.M., Grahmann, A., Giesinger, J.M., Wiesbauer, P., Sztankay, M., ... Holzner, B. (2012). Monitoring physical and psychosocial symptom trajectories in ovarian cancer patients receiving chemotherapy. BMC Cancer, 12, 7787. doi: 10.1186/1471-2407-12-77.

Perwitasari, D. A. (2009). Pengukuran kualitas hidup pasien kanker sebelum dan sesudah kemoterapi dengan EORTC QLQ-C30 RSUP Sardjito Yogyakarta. Majalah Farmasi Indonesia, 20(2), 68-72.

So, W.K., Chow, K.M., Chan, H.Y., Choi, K.C., Wan, R.W., Mak, S.S., ... Chan, C.W. (2014). Quality of life and most prevalent unmet needs of chinise breast cancer survivor at one year after cancer treatment. European Journal of Oncology Nursing, 18, 323-328. http://dx.doi.org/10.1016/j.ejon.2014. 03.002 .

Susilowati, Y.A. (2012). Faktor-faktor yang memepengaruhi kualitas hidup pada survivor kanker payudara. Universitas Indonesia. Tesis (Tidak dipublikasikan).

Vella, E. J., \& Budd, M. (2011). Pilot study: Retreat intervention predicts improved quality of life and reduced psychological distress among breast cancer patients. Complementary Therapies in Clinical Practice, 17(4), 209-214. http://doi.org/10.1016/j.ctcp.2011.01. 005 